\title{
OS POSSÍVEIS IMPACTOS ECONÔMICOS CAUSADOS PELA DEFASAGEM DO IRPF
}

\author{
THE POSSIBLE ECONOMIC IMPACTS CAUSED BY THE IRPF LAG
}

Elisângela Aparecida B. L. Zeri Bacharela em Ciências Contábeis pela Faculdade de Educação e Meio Ambiente - FAEMA, Ariquemes/RO.

E-mail: elisangelalopes1610@gmail.com

Thyago Vinicius M. Oliveira MBA em Gestão em Instituições Públicas pelo Instituto Federal de Rondônia IFRO. Docente na Faculdade de Educação e Meio Ambiente - FAEMA, Ariquemes/RO.

E-mail: thyago.vinicius@faema.edu.br.

\section{Weslei Gonçalves Borges}

Especialista em Planejamento Educacional e Docência do Ensino Superior pelas Faculdades Associadas de Ariquemes - FAAR. Docente na Faculdade de Educação e Meio Ambiente - FAEMA, Ariquemes/RO.

E-mail: weslei0204@gmail.com.

Submetido: 13 nov. 2021.

Aprovado: 5 dez. 2021.

Publicado: 14 dez. 2021.

\section{E-mail para correspondência:}

thyago.vinicius@faema.edu.br

Este é um trabalho de acesso aberto e distribuído sob os Termos da Creative Commons Attribution License. A licença permite o uso, a distribuição e a reprodução irrestrita, em qualquer meio, desde que creditado as fontes originais.

Imagem: StockPhotos (Todos os direitos reservados).

\section{Open Access}

Resumo: O Imposto de Renda da Pessoa Física é um tipo tributo, sua tabela é progressiva e vem sendo considerado um dos impostos mais importante do país. A atualização da sua tabela é essencial para reverter a injustiça ocasionado pelo sistema tributário, desde o início ela não acompanha a inflação do país, sendo atualizada conforme a lei vigente de cada ano, porém a última atualização aconteceu em 2015 e desde então essa desatualização vem afetando a população, em especial a classe média, dando a entender que eles possuem um poder aquisitivo maior do que a sua realidade. Diante de tantos acontecimentos que surgiram ao longo desses anos, principalmente em $2020 \mathrm{com}$ a pandemia da Covid 19 que foi necessário tomar medidas rigorosas para reduzir a propagação do vírus, fez com que a modificação na tabela fosse adiada mais uma vez, afetando sobretudo aqueles com renda mais baixa que deveriam ser isentas caso acompanhasse a inflação, em contrapartida caso seja atualizada isso gerará perdas consideráveis para o país. Essa pesquisa apresenta os efeitos econômicos à população ocasionado pela não atualização da tabela do IR, e como a defasagem atinge-os, explanando também o que acarretará ao Estado caso seja atualizada. Para um melhor entendimento sobre o tema, será discutido o conceito, finalidade e seu histórico no Brasil. Com tantas falhas não somente no sistema tributário, quem sempre acaba arcando com as consequências é a população, que muitas vezes por serem leigas no assunto acaba ignorando a importância da atualização da tabela do IRPF.

Palavras-chave: Imposto de Renda. IRPF. Sistema Tributário. Impacto econômico.

Abstract: Individual Income Tax is a type of tax, its table is progressive and has been considered one of the most important taxes in the country. Updating your table is essential to reverse the injustice caused by the tax system, since the beginning it does not follow the country's inflation, being updated according to the current law of each year, but the last update took place in $\mathbf{2 0 1 5}$ and since then this outdatedness has been affecting the population, especially the middle class, implying that they have a higher purchasing power than their reality. In view of so many events that have emerged over these years, especially in 2020 with the Covid 19 pandemic, which required strict measures to reduce the spread of the virus, caused the modification in the table to be postponed once again, affecting especially those with lower income that should be exempt if it followed inflation, on the other hand, if updated, it will generate considerable losses for the country. This research presents the economic effects on the population caused by not updating the IR table, and how the gap affects them, also explaining what it will entail for the State if it is updated. For a better understanding of the subject, the concept, purpose and its history in Brazil will be discussed. With so many failures not only in the tax system, who always ends up bearing the consequences is the population, who often, because they are laypeople on the subject, end up ignoring the importance of updating the IRPF table.

Keywords: Income Tax. IRPF. Tax system. Economic impact. 


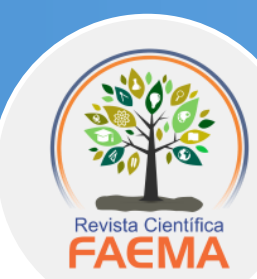

Introdução

No Brasil existe um imposto conhecido como imposto de renda que surgiu no ano de 1922, ano em que foi instituído definitivamente no Brasil, ele é um tipo de tributo, incidente sobre os rendimentos da pessoa física e jurídicas no ano-calendário, ou seja, ano que aconteceu o fato gerador da declaração que precisará ser entregue. 0 contribuinte pagará uma porcentagem sobre a renda obtida em determinado período, ela irá variar de acordo com a faixa estabelecida na tabela do IR, quanto mais superiores forem os rendimentos, maior será a alíquota incidente ${ }^{(1)}$.

Com a desvalorização do real, o desemprego e o poder de compra que diminui todos os anos, a economia brasileira sofre constantes mudanças todo ano, e isso também acaba afetando no IR, pois a tabela deveria acompanhar esse processo e ser atualizada, porém não é o que acontece, e isso acabou resultando em uma defasagem de $113 \%$, pois a última correção foi feita em $2015^{(2)}$.

Os problemas ocasionados pela pandemia do Covid-19 provocaram uma desordem econômico-social, trouxe inúmeros impactos na vida dos indivíduos do mundo todo. Todas as medidas utilizadas para conter a proliferação do vírus, a inflação, e outros componentes, desvalorizou ainda mais o Real, resultando em impactos significativos para muitas pessoas. Com os gastos realizados pelo governo federal, a correção da tabela do IR acabou não acontecendo, segundo o IPCA, a inflação de 1996 a 2020 ficou em torno de $346,69 \%{ }^{(3)}$.

Perante vários obstáculos que o Brasil vem enfrentando o que ocasionou o adiamento da atualização da tabela do IR, aproximadamente 10,5 milhões de pessoas deveriam estar dispensas da declaração do imposto. Em 2015 houve um pequeno reajuste de 5,6\% feito pela presidente Dilma Rousseff, porém o índice que foi aplicado é inferior à inflação do mesmo ano. 


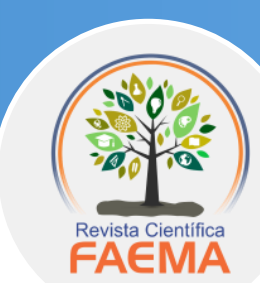

No ano de 2016 não houve atualização mesmo a inflação estando em 6,29\%, desse ano até os dias atuais não houve mais atualizações na tabela do imposto de renda. Em 2020 com tantos impasses, a inflação foi de 4,52\%, ou seja, a atualização não vem acompanhando essas mudanças desde muito tempo ${ }^{(4)}$.

O que essa desatualização significa na prática? O brasileiro acaba pagando mais imposto, e segundo Takar (4), aqueles com salários mais baixos são os mais atingidos pela defasagem. A finalidade da presente pesquisa é mostrar a perda no poder de compra do contribuinte no período e quanto deveria ser a tabela do IR se fosse acompanhar a inflação, apresentando o impacto do congelamento na tabela no cálculo do imposto de renda da pessoa física.

O objetivo principal é apresentar, através da revisão de literatura, um cálculo de atualização da tabela do Imposto de Renda, apontando os efeitos econômicos da não atualização. Os objetivos secundários são: apresentar conceito de tributos e do IR, bem como o ano de sua criação e sua finalidade; identificar os impactos financeiros causado pela falta da correção da tabela do IR e evidenciar a defasagem que vem sendo acumulado desde 1996.

\section{Revisão de Literatura}

\section{Conhecimentos gerais sobre tributos}

Preliminarmente será apresentado o conceito de tributo, pois o imposto é um de suas espécies, como será visto posteriormente. De acordo com o que está previsto no artigo $3^{\mathrm{a}}$ da Lei $\mathrm{n}^{\circ} 5.172 / 66$, expresso no Código Tributário Nacional, tributo é uma obrigação que resulta independente da vontade do sujeito passivo, sendo feito em dinheiro, porém poderá ser feito por algo que possui valor e que ele seja equivalente à moeda, somente a lei poderá criá-lo, alterar e excluí-lo ${ }^{(5)}$. 


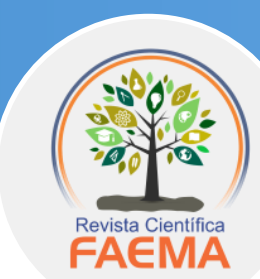

O tributo é gênero, sendo composto por cinco espécies, impostos, taxas, contribuição de melhoria, contribuição especiais e empréstimo compulsório. A tributação possui um grande papel, pois através dos tributos, o governo arrecada recursos necessários para sustentar os gastos das atividades estatais, e concede bens e serviços para a comunidade, pois o Estado sozinho não gera receita, então é necessário gerar de alguma forma e isso vem através dos impostos ${ }^{(6)}$.

O primeiro tributo do Brasil, foi instituído pela coroa portuguesa no período colonial. Levando em consideração a pequena população e a ausência de comércio relevante, viu-se uma oportunidade com a lucratividade da exploração do pau-brasil, com isso, surge então o tributo chamando "quinto do pau-brasil" (7). Seu nome representa a alíquota fiscal e também a forma de pagamento, como a moeda portuguesa ainda não havia sido adotada no país nessa época, o pagamento era realizado com um quinto da parte da madeira da árvore do pau-brasil ${ }^{(8)}$.

\section{Breve histórico do imposto de renda}

Segundo alguns historiadores, o imposto de rende surgiu no ano de 1404, porém devido aos documentos que tratava da arrecadação terem sido queimado, não dá para saber com exatidão o ano e o país que surgiu o imposto de renda, considera-se que tenha surgido no ano de 1904, porém grande parte deles acreditam que se iniciou realmente em 1799 na Inglaterra, pois pelo fato de sofrer ameaças por parte de Napoleão Bonaparte, precisava coletar recursos para custear a guerra (9).

No Brasil, desde 1843, o império já planejava cobrar tributos da renda das pessoas, no ano de 1867, foi criado a Lei 1.507 com o intuito de cobrar imposto sobre vencimentos, no que tange em seu artigo 22 , no entanto mais uma vez não obteve êxito. Já em 1891, com Rui Barbosa, Ministro da Fazenda na época, era favorável sobre a tributação sobre a renda, porém a Lei Maior não trouxe essa previsão ${ }^{(9)}$. 


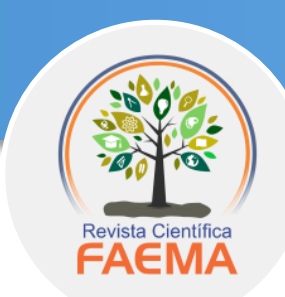

Com a República, o governo sente a necessidade de uma fonte de renda que pode ser fornecido com a criação de um imposto. Com isso, em 1951 surge a Lei $n^{\circ} 4.440$ trouxe a previsão Imposto de renda, entretanto não considerava a capacidade contributiva do sujeito passivo ${ }^{(10)}$.

Já em 1922, com a Lei n 4.625 foi instituído o Imposto de Renda no Brasil, sendo declarado todo início do ano por pessoas físicas e jurídicas que residem no país. Nos primeiros anos a participação na receita tributária do Brasil era mínima, ficando em torno de $3 \%$, ou seja, alcançando cerca de 6.436 .980 contribuintes, porém foi aumentando de forma gradativa, em 2021 a Receita Federal alcançou mais de 34 milhões de declarações ${ }^{(11)}$. Por se tratar de um imposto recente, foi muito criticado e muitos alegaram que a administração pública iria invadir a privacidade, pois teriam acesso à renda de toda população ${ }^{(12)}$.

Até o ano de 1988 não havia leis para definir as variações das alíquotas, elas eram aplicadas de forma progressiva, ou seja, era feito de acordo com o montante dos rendimentos tributáveis do contribuinte, essa modificação ocorreu com a implementação da Constituição da República Federativa do Brasil de 1988 que dispôs que deveria ser cobrado de acordo com a lei vigente, isso mudou o conceito da IRPF, que reduziu o número de alíquotas e o percentual da alíquota máxima aplicada ${ }^{(13)}$.

\section{Conceitos e características do IR}

O imposto de renda é um tributo federal, que de acordo com a CF, art. 153 em seu inciso III, é de competência da União, sendo gerado sobre a renda e proventos de qualquer natureza, no mesmo artigo encontra-se estabelecido os critérios da generalidade, universidade e progressividade ${ }^{(14)}$. 


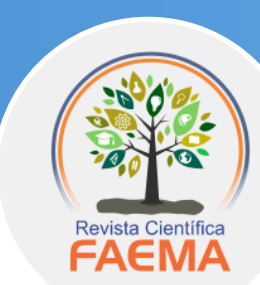

Pela generalidade, todas as pessoas físicas e jurídicas que obterem rendas ou proventos serão tributados, já pela universidade estipula a tributação das rendas e proventos, onde o campo de incidência do imposto precisa ser o mais amplo possível e por fim, a progressividade entende que as alíquotas sejam de acordo com a capacidade de econômica de cada contribuinte ${ }^{(6)}$.

De acordo com Dubard ${ }^{(15)}$, o imposto é um tributo sobre a renda, e acompanha a evolução patrimonial, para declará-lo é preciso realizar o download do programa disponibilizado pela Receita Federal em seu próprio site. Será declarado todos os ganhos, bens e despesas que ocorreram no ano anterior, como o salário anual, carro, casa, escola, faculdade, plano de saúde, caso seja pago pelo contribuinte. Os valores arrecadados são destinados à saúde, educação, programas sociais, como por exemplo, bolsa família, oferecido pelo Governo com objetivo de garantir uma condição de vida melhor para famílias de extrema pobreza, ou ajudá-las a superar tal situação (16).

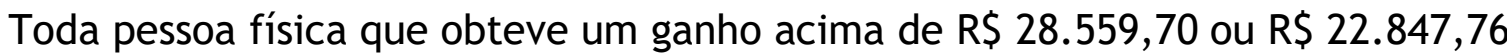
e recebeu o auxílio emergencial, rendimentos não-tributáveis e isentos maiores de R\$ $40.000,00$, ou que tiveram posse ou propriedade de bens acima de $\mathrm{R} \$ 300.000,00$ no ano de 2020, deverão fazer sua declaração. São isentos trabalhadores com renda mensal até R\$ $1.903,98$, pessoas portadoras de doenças graves, como cegueira, paralisia irreversível e incapacitantes, entre outros, porém é importante salientar que a isenção não é automática, para obter tal benefício, é necessário ter um laudo do médico do Sus, e apresentá-lo juntamente com um formulário em alguma unidade da Receita Federal (17).

A Receita Federal também considera criptoativos, moeda virtual protegido por criptografia, por não ter regulamentação exclusiva para si no Brasil, não pode ser considerado uma aplicação financeira, então é necessário informá-lo no campo bens e direito pelo seu custo de aquisição, vale destacar que o valor deve ser igual ou até mesmo acima de $\mathrm{R} \$ 5.000,00{ }^{(18)}$. 


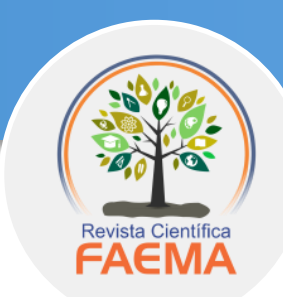

Todas as declarações são recepcionadas pela RFB e são examinadas eletronicamente a partir da recepção e considera as informações de terceiros, havendo divergência entre a declaração e as informações fornecidas, o sistema separa para uma observação mais precisa. A DIRPF é recolhida em malha fiscal, também conhecido por "cair na malha fina", irá ficar retida até que seja tudo solucionado ou até que seja apresentado algum documento que possa comprovar a incompatibilidade que foi constatado eletronicamente ${ }^{(19)}$.

Uma das principais causam que levam a declaração a cair na "malha fria" é a discordância entre os rendimentos e do imposto de renda retido na fonte, incoerências do valor dos gastos médicos e valores de pensão alimentícios que foram declarados, entre outros ${ }^{(20)}$. Caso o contribuinte perceba falhas em sua declaração ou que a mesma esteja incompleta, pode-se fazer a declaração retificadora, ou seja, enviar outra declaração com as informações já ajustadas, pode ser enviada de três formas, pelo programa IRPF, pelo e-CAC ou pelo aplicativo Meu imposto de renda disponibilizado também para tablet e smartphones, porém tem-se até somente até o última dia da declaração especificado pela Receita Federal, para fazer os devidos reajustes e assim entregar a declaração retificadora ${ }^{(21)}$.

Além da Receita Federal, os impostos também são controlados pelo fisco, ele é a autoridade fazendária, ou seja, fiscaliza e controla os pagamentos de impostos, ele é o órgão fiscalizador de toda legislação tributária do Brasil, dividido em Federal, Estadual e Municipal. O fisco federal administra os impostos federais, e o mais conhecido é o IR (22).

A tabela do IRPF é constituída pela base de cálculo, alíquotas e parcelas a deduzir. A parte da base de cálculo é a renda, refere-se aos rendimentos que são tributáveis no IR, é por ele que será feito todo o cálculo para saber o quanto será pago, sendo diferente em cada uma das 5 faixas. 


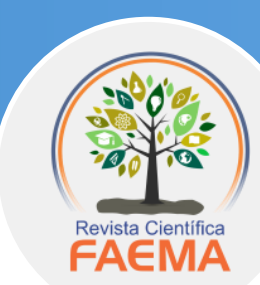

A alíquota é percentual que será usado para saber o quanto será pago, já as parcelas a deduzir, é valor que deverá ser descontado, sua existência se deve ao fato de que os rendimentos até $\mathrm{R} \$ 1.903,98$ não são tributáveis, ou seja, estão isentas do imposto, não sendo obrigatório a declaração para os estão nessa faixa de renda (23).

Durante a declaração, o contribuinte pode estar fazendo doações diretamente dela pode diminuir até $3 \%$ do imposto e destinando esse valor à alguma entidade, caso deseja fazer a doação, ela irá para o Conselho do idoso e da Criança e do Adolescente, porém somando-se a deduções, e outros fundos, limita-se até 6\%. As deduções são os valores que podem ser diminuídos da declaração, são os gastos com saúde, educação, entre alguns outros ${ }^{(24)}$.

O imposto de renda não é recolhido sobre todo salário, por exemplo, o que foi descontado do INSS não entra para fins de cálculo do IR, e mais, as alíquotas não são cobradas integralmente sobre a renda, é preciso fazer a devidas deduções encontradas na tabela, primeiramente é preciso encontrar a base de cálculo, multiplicar pela alíquota incidente, do seu resultado será feito as deduções ${ }^{(25)}$.

Todos aqueles que declaram seu imposto de renda, quando há saldo a ser recebido, tem direito à restituição, ela nada mais é que a devolução do valor que foi pago a mais para a Receita Federal, se durante a entrega da declaração houver uma diferença positiva indicada, representa que o contribuinte deve pagar a diferença, mas caso contrário, irá receber essa quantia em sua conta bancária especificada (26).

Nos primeiros lotes é dado preferência ao grupo prioritário no pagamento, sendo eles idosos, pessoas com deficiência, professores, e aqueles que enviaram sua declaração no prazo de entrega no mês de março, em 2021 serão efetuados pagamentos no valor de $\mathrm{R} \$ 6$ bilhões somente nesse primeiro lote da restituição ${ }^{(27)}$. 


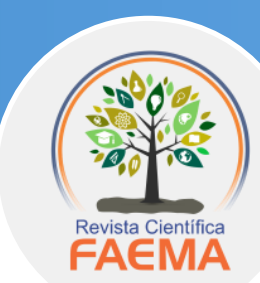

Deve-se estar sempre atento aos prazos da declaração para que dessa forma não sejam penalizados, pois se caso perder o prazo, estará sujeito a pagar multas equivalentes a $R \$ 165,74$, já para aquele que tem imposto devido a multa é de $1 \%$ ao mês, limitando-se a 20\%. Para aqueles que não entregar a declaração, a multa chega a 75\% do imposto devido ${ }^{(28)}$.

O IR é um imposto não vinculado, ou seja, diferente de outros, como por exemplo, as taxas de lixo onde o contribuinte paga-o e em troca é feito a coleta dos resíduos. O imposto de renda é utilizado de forma generalizada, o Estado fará a distribuição devolvendo aquilo que foi recolhido em melhorias, dando importância a destinação para atender as despesas gerais da administração pública ${ }^{(29)}$.

\section{Tabela do IR: atualizações e os efeitos}

Com a introdução do Plano Real no ano de 1994, a economia do Brasil começou se estabilizar, porém ainda tinha um extenso caminho a percorrer e obstáculos a serem superados, entre vários deles estava a crise fiscal. Até o ano de 1995, a tabela do imposto de renda era atualizada periodicamente, ocorrendo todos os anos de forma regular. No mesmo ano no dia 26 de dezembro surge o pronunciamento da Lei $9.250 / 1995$, onde a tabela é convertida para o Real, até então, os valores eram expressos em UFIR - Unidade Fiscal de Referência, com isso surge a necessidade da existência de uma faixa de alíquota. Para suprir o déficit e o endividamento público, que antes disso não acontecia, a tabela ficou congelada de 1996 a 2001 e foi a primeira tabela em Reais (30).

Segundo Kanitz et al. (30), a base de cálculo acima de R\$900,01 a R\$1.800,00 com alíquota de $15 \%$, acima de $\mathrm{R} \$ 1800,01$ com alíquota de $25 \%$, permaneceu o mesmo por seis anos mesmo com a estabilidade econômica. 


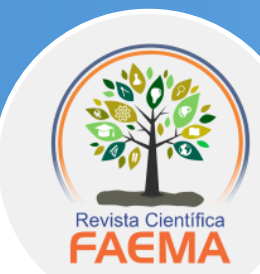

Em 2002 com a Lei 10.451/2002 surge uma nova tabela progressiva que fica desatualizada até o ano de 2004, a partir disso a tabela sofre pequenos reajustes, e em 2009 a alíquota 22,5\% é introduzida conforme a Lei 11.495/09. A tabela do Imposto de renda é renovada ano a ano de acordo com as leis pronunciada e não conforme o IPCA, o que acaba fazendo com que a dafasagem aumente (30). De acordo com o IBGE, IPCA é o índice de preço ao consumidor amplo, que mede a inflação de produtos e serviços comercializados no varejo.

Tabela 1- Índice de Preço ao Consumidor Amplo (IPCA) acumulado- 1996 a 2020

\begin{tabular}{|c|c|}
\hline ANO & IPCA (acumulado) \\
\hline 1996 & 9,56 \\
\hline 1997 & 5,22 \\
\hline 1998 & 1,66 \\
\hline 1999 & 8,94 \\
\hline 2000 & 5,97 \\
\hline 2001 & 7,67 \\
\hline 2002 & 12,53 \\
\hline 2003 & 9,30 \\
\hline 2004 & 7,60 \\
\hline 2005 & 5,69 \\
\hline 2006 & 3,14 \\
\hline 2007 & 4,46 \\
\hline 2008 & 5,90 \\
\hline 2009 & 4,31 \\
\hline 2010 & 5,91 \\
\hline 2011 & 6,50 \\
\hline 2012 & 5,84 \\
\hline 2013 & 5,91 \\
\hline 2014 & 6,41 \\
\hline 2015 & 10,67 \\
\hline 2016 & 6,29 \\
\hline 2017 & 2,95 \\
\hline 2018 & 3,75 \\
\hline 2019 & 4,31 \\
\hline 2020 & 4,52 \\
\hline
\end{tabular}

Fonte: IDinheiro (2021) 
A defasagem é a diferença que deveria ser cobrada da população levando em consideração todo cenário econômico do país, seu cálculo leva em conta a inflação acumulada de todos esses anos, mesmo com as correções já realizadas entre esses períodos ${ }^{(31)}$. Desde 1996, a tabela não acompanha a inflação, e consequentemente acaba fazendo com que o contribuinte pague mais imposto do que pagava no ano anterior, e durante esses 24 anos a defasagem se acumula em aproximadamente 113,09\% (32). A inflação é o acréscimo nos preços dos bens e serviços, que acarreta a diminuição do poder de compra, no Brasil há diversos índices de preço, porém é o IPCA que é utilizado no sistema de metas para a inflação ${ }^{(33)}$. De acordo com o IPCA, a inflação de 1996 a 2020, ficou em torno de 391,69\%, e segundo o Banco Central do Brasil, a correção ficou em torno de 109,63\%, valor bem abaixo do necessário, sendo perceptível que o devido imposto não acompanha esse aumento contínuo nos preços da economia.

Tabela 2- Cálculo de atualização da tabela do Imposto de renda em (\%)

\begin{tabular}{c|c|c|c|c} 
Períodos & IPCA & Correção da Tabela & Resíduos & Resíduos Acumulado \\
\hline 1996 & $9,56 \%$ & - & $9,56 \%$ & $9,56 \%$ \\
\hline 1997 & $5,22 \%$ & - & $5,22 \%$ & $15,28 \%$ \\
\hline 1998 & $1,66 \%$ & - & $1,66 \%$ & $17,19 \%$ \\
\hline 1999 & $8,94 \%$ & - & $8,94 \%$ & $27,67 \%$ \\
\hline 2000 & $5,97 \%$ & - & $5,97 \%$ & $35,29 \%$ \\
\hline 2001 & $7,62 \%$ & - & $7,62 \%$ & $45,60 \%$ \\
\hline 2002 & $12,53 \%$ & $17,50 \%$ & $-4,23 \%$ & $39,44 \%$ \\
\hline 2003 & $9,30 \%$ & - & $9,30 \%$ & $52,41 \%$ \\
\hline 2004 & $7,60 \%$ & - & $7,60 \%$ & $63,99 \%$ \\
\hline 2005 & $5,69 \%$ & $10,00 \%$ & $-3,92 \%$ & $57,57 \%$ \\
\hline 2006 & $3,14 \%$ & $8,00 \%$ & $-4,50 \%$ & $50,48 \%$ \\
\hline 2007 & $4,46 \%$ & $4,50 \%$ & $-0,04 \%$ & $50,42 \%$ \\
\hline 2008 & $5,90 \%$ & $4,50 \%$ & $1,34 \%$ & $52,43 \%$ \\
\hline 2009 & $4,31 \%$ & $4,50 \%$ & $-0,18 \%$ & $52,16 \%$ \\
\hline 2010 & $5,91 \%$ & $4,50 \%$ & $1,35 \%$ & $54,21 \%$ \\
\hline 2011 & $6,50 \%$ & $4,50 \%$ & $1,91 \%$ & $57,16 \%$ \\
\hline 2012 & $5,84 \%$ & $4,50 \%$ & $1,28 \%$ & $59,18 \%$ \\
\hline 2013 & $5,91 \%$ & $4,50 \%$ & $1,35 \%$ & $61,33 \%$ \\
\hline 2014 & $6,41 \%$ & $4,50 \%$ & $1,83 \%$ & $64,27 \%$ \\
\hline 2015 & $10,67 \%$ & $5,60 \%$ & $4,80 \%$ & $72,16 \%$ \\
\hline 2016 & $6,29 \%$ & - & $6,29 \%$ & $82,99 \%$ \\
\hline 2017 & $2,95 \%$ & - & $2,95 \%$ & $88,39 \%$ \\
\hline 2018 & $3,75 \%$ & - & $4,75 \%$ & $103,88 \%$ \\
\hline 2019 & $4,31 \%$ & - & $4,52 \%$ & $13,09 \%$ \\
\hline
\end{tabular}




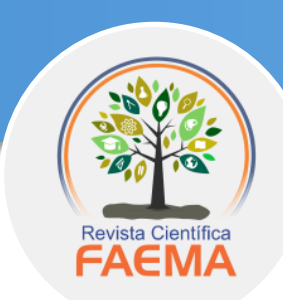

Como pode-se perceber com a tabela acima, a primeira correção na tabela foi feita em 2002, e foi o maior reajuste realizado tendo sua continuidade até 2005, sendo feito atualizações anualmente, porém de 2007 a 2014 elas foram de igual valor, tendo sua última atualização de 5,60 \% em 2015.

Se esse valor da defasagem fosse aplicado, o valor iria passar de $\mathrm{R} \$ 1.903,98$ para R\$ 4.022,89, ou seja, aproximadamente 10 milhões de pessoas ficariam isentas da declaração ${ }^{(34)}$. Já as deduções legais que são lançadas dobrariam o seu valor, o desconto por dependente iria de $\mathrm{R} \$ 2.275,08$ para $R \$ 4.646,40$, os gastos com educação que está limitada a $R \$ 3.561,50$, passaria para $R \$ 7.260,83^{(4)}$.

O IRPF 2021, é regulamentado pela Instrução Normativa RFB n².010, do dia 24 de fevereiro de $2021^{(35)}$. Abaixo segue a tabela com os valores vigentes da atual tabela, e como seria esses valores se caso tivesse feito a correção.

Tabela 3- Base de cálculo vigente e corrido sem a defasagem de 113,09\%

BASE DE CÁLCULO

\begin{tabular}{|c|c|c|}
\hline Atual & Corrigido (113,09\%) & quota \\
\hline Até R\$ 1903,98 & $\mathrm{R} \$ 4.057,23$ & pento \\
\hline De R\$ 1.903,99 - R\$ 2.826,65 & De R\$ 4.057,24 - R\$ 6.023,30 & $7,5 \%$ \\
\hline De R\$ 2.826,66 - R\$ 3.751,05 & De $R \$ 4.057,24-R \$ 6.023,30$ & $15 \%$ \\
\hline De R\$ 3.751,06 - R\$ 4.664,68 & De R\$6.023,31 - R\$ 9.939,97 & $2,5 \%$ \\
\hline Acima de $\mathrm{R} \$ 4.664,68$ & Acima de $R \$ 9.939,97$ & $27 \%$ \\
\hline
\end{tabular}

Fonte: Dos autores (2021)

De acordo com a tabela apresentada acima, pode-se perceber a grande diferença nos valores, a defasagem causa grande impactos, sem ela os valores mudam drasticamente. Há um Projeto de Lei que ainda está em discussão no Senado Federal. A PL 2337/21 visa reajustar a tabela, deixando isentos aqueles que recebem até $\mathrm{R} \$$ 2.500,00 por mês, no entanto, os lucros e dividendos das empresas começarão a serem taxadas em $15 \%{ }^{(32)}$. 


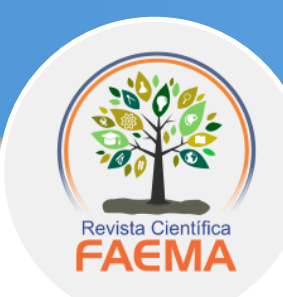

Como foi mencionado anteriormente, a tabela do IR é feita de acordo com lei vigente, o que não traz nenhum benefício a população, pois o fato de não acompanhar a inflação e/ou a não atualização, faz com que os contribuintes obrigados paguem uma alíquota maior que o anterior, e isso é mais prejudicial para aqueles que possuem renda tributável menor (36).

As deduções existem e estão presentes, porém elas não são compatíveis com o preço dos serviços, por exemplo, na educação o valor a ser deduzido é de $\mathrm{R} \$ 3.561,50$ por dependente por ano, o que ficaria em torno de $\mathrm{R} \$ 300,00$ por mês em uma escola, e encontrar uma nesse valor não é fácil, isso gera um descompromisso social, penalizando duplamente as famílias no Brasil, os preços aumentam e a tabela continua intacta desde a última atualização ${ }^{(37)}$.

Nos últimos 26 anos, o real perdeu 84\% do seu poder de aquisição, com inflação já acumulada isso significa, por exemplo, que com uma cédula de $\mathrm{R} \$ 100,00$, o brasileiro passou a comprar apenas 16\% do que comprava em 1994 (38). É importante ressaltar que o preço médio da cesta básica de várias capitais do país sofreu aumentos significativos, em São Paulo, por exemplo, o valor chegou a R\$ 631,46, ou seja, esse valor corresponde a 53,45\% do salário-mínimo (38). As famílias do Brasil que recebem até 1,9 mil comprometem a maior parte de seus ganhos com alimentação, habitação e transporte (39).

Gráfico 1: Gasto médio familiar mensal no país por tipo de despesa

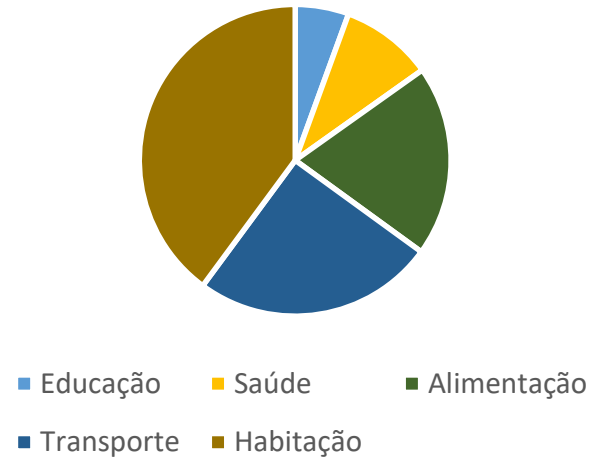

Fonte: G1 (2020) 


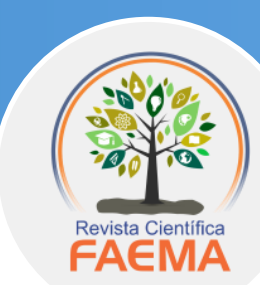

Em média, a despesa no consumo mensal das famílias brasileiras, foram de R\$ 4.411,60 e cerca de 8\% desse valor é imposto, os gastos foram educação: $R \$ 205,61$, saúde $R \$ 354,79$, alimentação $R \$ 732,54$, transporte $R \$ 927,67$ e habitação $R \$ 1.473,79$ (38). Os reajustes salariais anuais mesmo sendo abaixo da inflação, acaba fazendo com que o cidadão entre para uma outra faixa de renda da tabela, ou aqueles que eram isentos tornam-se contribuinte, isso é mais sentido na classe média da tributação, um contribuinte que recebe em torno de $\mathrm{R} \$ 5.000,00$, com a defasagem na tabela, essa pessoa acaba pagando $\mathrm{R} \$ 432,00$, ou seja, $590 \%$ maior do valor que seria pago, caso tivesse sido atualizada ${ }^{(38)}$.

Sabe-se que o IR tributa o contribuinte de acordo com sua renda, ao observar a tabela, é perceptível que as alíquotas além de serem baixas, atinge em grande parte a classe média, sendo prejudicial se tratando de finanças, pois independente da condição social, ele também pagará os mesmos impostos em cima da cesta básica, como uma pessoa com renda mais alta, com isso, a tabela não atualizada acaba classificando-o como um cidadão com renda maior ${ }^{(40)}$.

O sistema tributário atual do Brasil, está indiferente com a realidade financeira, o fato de tributar aquele com renda inferior de maneira agressiva, obtendo parcela significativa daqueles que não tem poder aquisitivo suficiente para assegurar suas necessidades básicas, acaba cometendo injustiças e assim prejudicando-o, para isso é necessária uma nova política de tributação, se atentar à atual realidade da grande parte dos brasileiros ${ }^{(41)}$.

O princípio da capacidade contributiva, um dos critérios do CRFB/88 a fim de proteger o povo, dando-lhes garantia de diminuir as diferenças por meio da tributação, vem sendo ferido pela desatualização da tabela, uma aplicação correta nas faixas, poderia ser listado como um direito do contribuinte. A falta de atualizar a tabela segundo a inflação anual, faz com que haja perda de poder aquisitivo e acaba lesionando o princípio a Constituição do Brasil de $1988{ }^{(7)}$. 


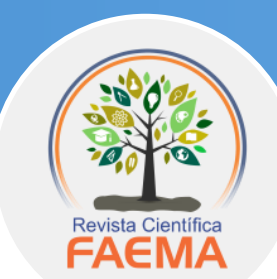

O gráfico a seguir apresenta uma comparação entre a tabela do IR atual e a tabela se caso houvesse uma atualização sem a defasagem.

Gráfico 2: Gráfico comparativo do valor atual da tabela e o valor sem a defasagem

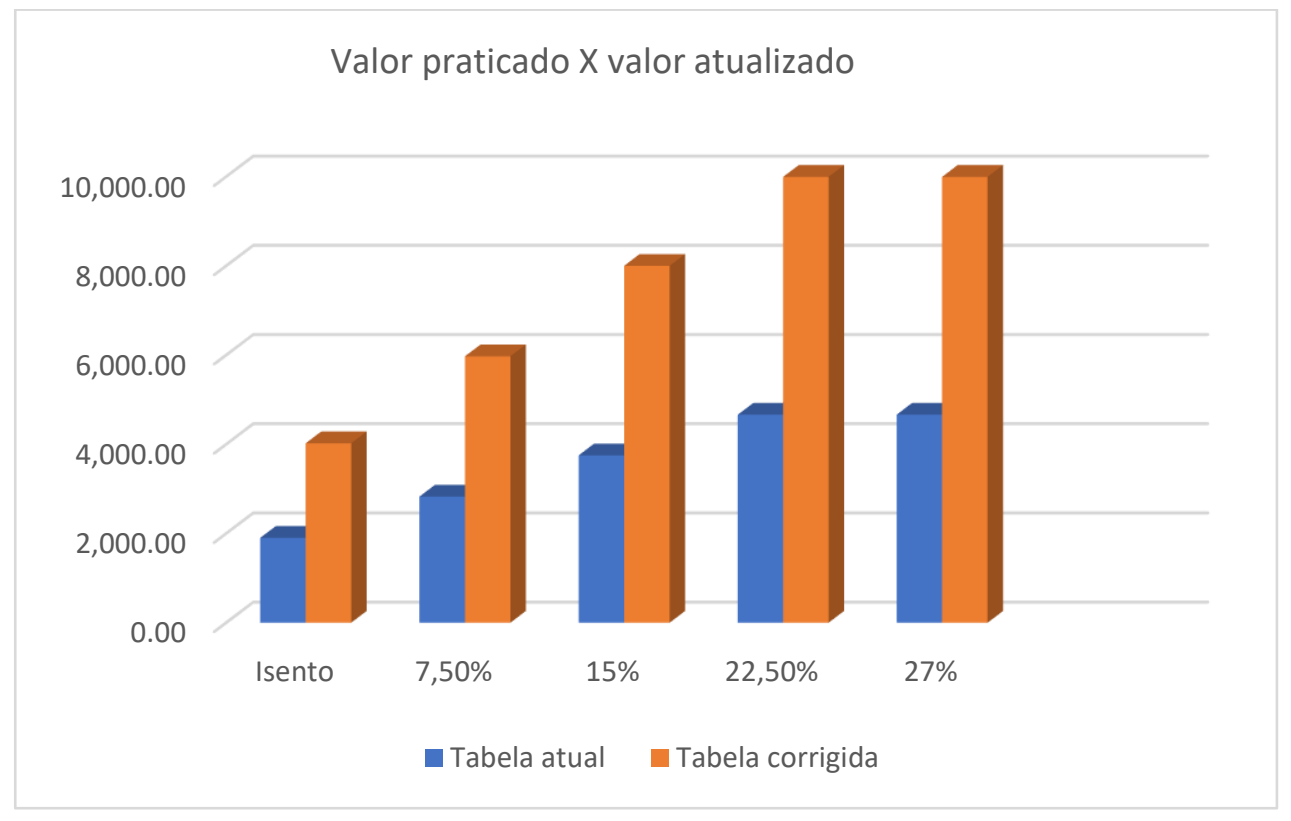

Fonte: Adaptado de G1 (35)

Com a correção da tabela até R\$ $3.000,00$ beneficiaria cerca de 4,3 milhões de contribuintes, em contrapartida isso também significaria ao cofre público um prejuízo de R\$ 74 bilhões, e com a correção da defasagem, essa perda subiria para $\mathrm{R} \$ 111,78$ bilhões ${ }^{(42)}$.

Pode-se perceber que as alíquotas não são ajustadas desde 2015, e a tendência é aumentar cada vez mais o número de contribuintes, porém caso haja uma correção, nem que seja na primeira faixa de isenção, isso causará impactos de tributação, podendo não ser tão benéfico, pois o governo poderá tentar compensar esse prejuízo em outras fontes de tributos para gerar receita ao Estado e assim suprir seus gastos (42).

O gráfico a seguir apresenta a evolução da quantidade de declarações entregues dos últimos quatro anos, e logo em seguida, como ficaria se caso fosse corrigido a tabela. 


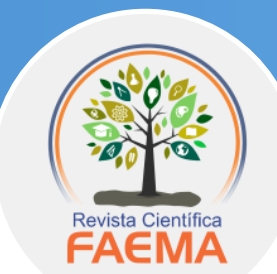

Gráfico 3: Número de contribuintes 2018-2021

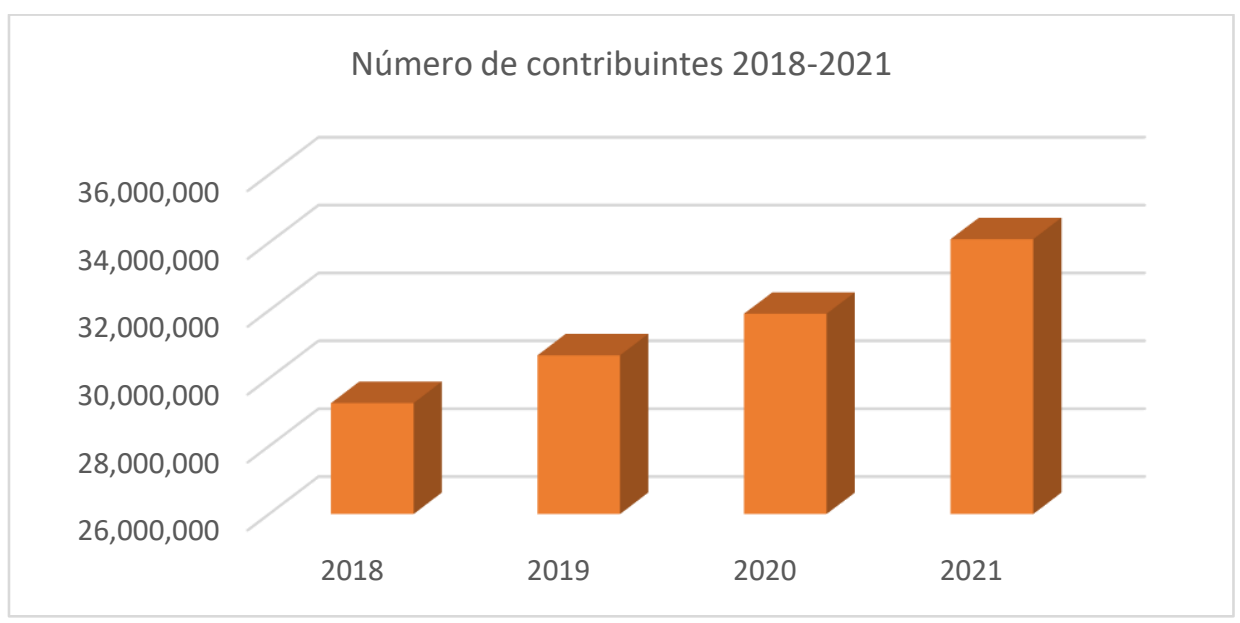

Fonte: Dos autores (2021)

É perceptível que a quantidade de declarações cresceu de forma gradativa, caso a tabela fosse corrigida, o Estado perderia aproximadamente 10 milhões de contribuintes e esses números iriam cair drasticamente ${ }^{(43)}$.

\section{Gráfico 4: Quantidade que diminuiria se a tabela fosse corrigida}

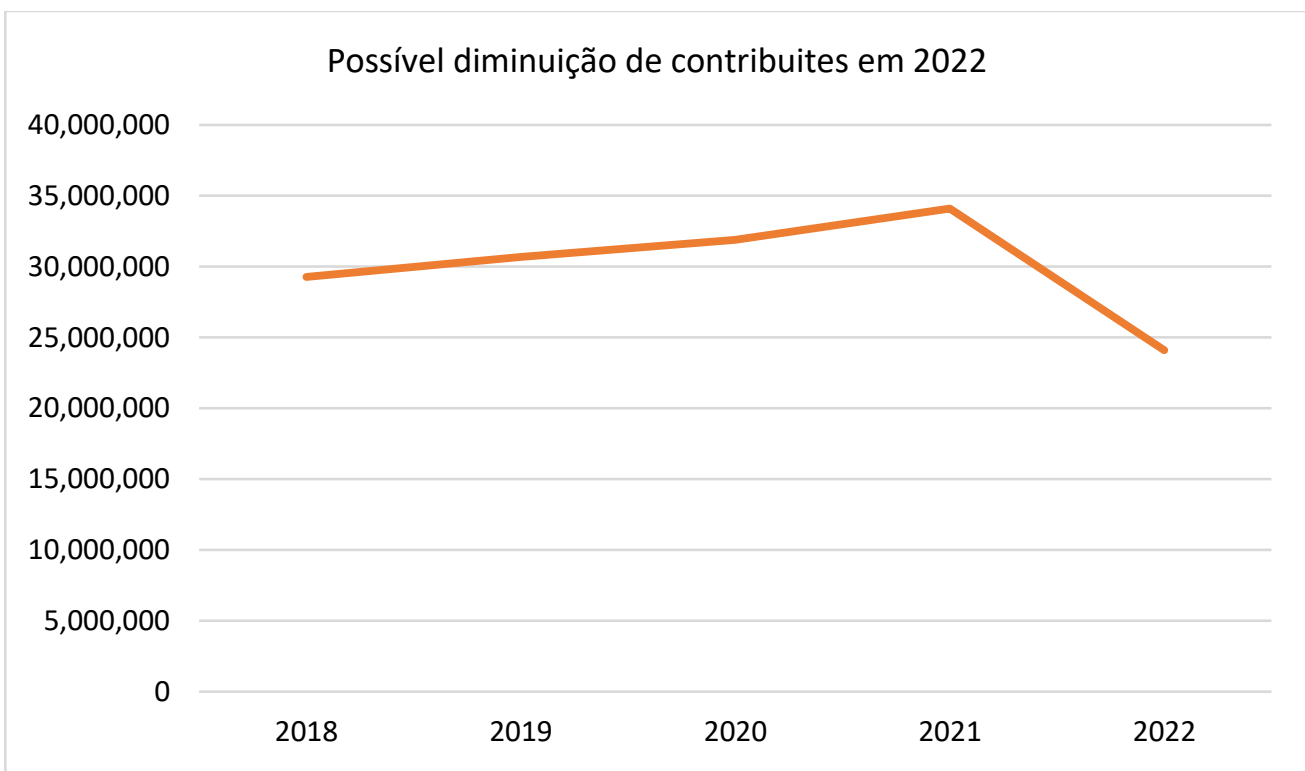

Fonte: Dos autores (2021) 


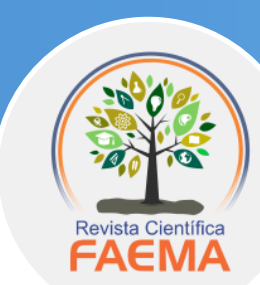

Visivelmente parece ser insignificante, porém para os cofres públicos representa uma grande perda na arrecadação, sabe-se que o IR é um dos impostos mais importantes do país, só no ano de 2018, foi arrecado cerca de R\$ 389 bilhões ${ }^{(44)}$. De acordo com o atual ministro da economia, Paulo Guedes uma possível atualização iria levar a uma diminuição de arrecadação, somente um aumento da faixa de isenção para R\$ 3 mil, iria causar uma perda de R\$ 22 bilhões, e chegaria a R\$ 36 bilhões caso a correção alcançasse todas as faixas da tabela (44).

A população brasileira além de serem penalizadas com a tabela do IR, onde as declarações são feitas no início do ano, há também o IPTU que juntamente com o IPVA, possui impactos significativos na renda das famílias da classe média, mesmo a tabela tendo alíquotas que aumenta conforme a renda, acaba perdendo o caráter progressivo, esses tributos desfavorecem grande parte dos cidadãos, eles já iniciam o ano tendo que sendo punidos com impostos tão elevados ${ }^{(41)}$.

Por ser considerado injusto, a reforma tributária no Brasil é algo bastante discutido, tanto entre especialistas, quanto pela população em geral, o IR acaba sendo um dos impostos mais polemizado pelo fato de incidir exatamente sobre a renda ${ }^{(12)}$. 0 atual ministro Paulo Guedes organiza uma pequena reforma, com um reajuste mínimo na tabela, com uma possível mudança no aumento de isenção, a qual poderia passar de R\$ $1.903,98$ para um valor abaixo de $R \$ 3.000,00$, segundo especulações, essa isenção pode ser para aqueles que recebem menos que $\mathrm{R} \$ 2.500,00{ }^{(45)}$.

A declaração do IRPF 2021, iniciou no dia $1^{\circ}$ de março de 2021 , e devido a prorrogação da Receita Federal finalizou no dia 31 de maio, nesse ano teve algumas mudanças, além das restituições serem pagas com mais antecedência do que nos demais anos, houve também a declaração do auxílio emergencial para àqueles que obtiveram rendimentos acima de $\mathrm{R} \$ 22.847,76$ no ano de 2020 , tendo que efetuar a devolução dos valores que foram recebidos, tanto o contribuinte, quanto seus dependentes. A Receita Federal também criou 3 tipos de criptoativos, no campo "Bens e direitos há os três atuais códigos ${ }^{(24)}$. 


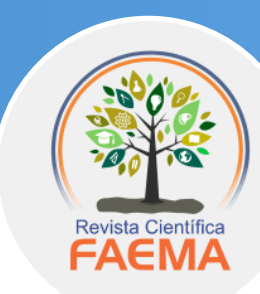

\section{Covid-19 X IRPF}

Em fevereiro de 2020, é detectado o primeiro caso de covid no Brasil, porém somente em março que houve a contaminação comunitária no país. Para conter a proliferação do vírus, foi necessário medidas drásticas, como lockdown, que prejudicou ainda mais a economia no país ${ }^{(46)}$. Além disso com o decreto de estado de calamidade pública, o governo gastou cerca de R\$ 524 bilhões, esses gastos foram com despesas adicionais do ministério da saúde que teve que fazer compras de remédios, máscaras, oxigênio, entre outros, e com a paralisação da economia, precisou oferecer ajuda para as pessoas que foram prejudicadas com isso, então o governo federal teve que conceder auxílios ${ }^{(47)}$.

Diante de todo ocorrido, dívidas crescendo e rombos ininterruptos, o governo decidiu adiar a atualização da tabela, e em 2020 as contas públicas foi fechada no “vermelho" pelo sétimo ano consecutivos, com uma projeção no valor de 831,8 bilhões de reais, podendo levar a dívida bruta do setor público a um nível próximo de $100 \%$ do PIB em $2021^{(48)}$.

O auxílio emergencial, foi instituído no ano de 2020 juntamente com o BEmBenefício Emergencial de Prevenção do Emprego e da Renda, tendo como principal objetivo de amenizar os impactos sociais causados pela covid-19 e preservar o emprego e renda, porém se aqueles que não são isentas, deverá declarar esses benefícios, é necessário ter as devidas atenções sobre os procedimentos exigidos para cada tipo de auxílio para não ter problema com o fisco ${ }^{(41)}$.

$\mathrm{O}$ atual presidente Jair Bolsonaro alegou que por conta do endividamento de R\$ 7 bilhões por causa da pandemia, não conseguiu colocar em prática as mudanças necessárias ${ }^{(41)}$. 
Para dificultar ainda mais, aqueles que se encaixam nas regras que obriga a declarar, e que receberam o auxílio emergencial proporcionado pelo Governo, terão que pagar o imposto sobre esses benefícios ${ }^{(37)}$.

Diante de tantos acontecimentos, a atualização da tabela do IR defrontou-se com uma grave crise fiscal do governo, onde ele tenta voltar a se equilibrar cortando as despesas e assim obter um superávit fiscal, ou seja, voltar a ter um ganho maior do que seus gastos ${ }^{(36)}$.

Apesar de tantas polêmicas a respeito da emergência atualização da tabela do imposto de renda, no ano de 2021 teve um aumento de cerca de 6,8\% comparado com o ano anterior, ou seja, a Receita Federal recebeu 34.168.166 declarações, superando a expectativa do Fisco, que havia previsto 34.089 .712 , isso se deu pelo fato de mais contribuintes decidiram entregar a declaração ${ }^{(49)}$.

\section{Metodologia}

A metodologia define como será realizado a coleta de dados para a elaboração da pesquisa, além disso dá um direcionamento para a produção do trabalho, através dela é possível descrever o tipo de pesquisa aplicado e definir fontes e instrumentos para a coleta de dados ${ }^{(50)}$.

Compreender os tipos de pesquisa é determinante para a elaboração do trabalho, ela pode ser classificada quanto à abordagem, natureza, objetivos e procedimentos técnicos utilizados no decorrer do estudo (51).

A classificação dessa pesquisa quanto à abordagem, é quantitativa. Na pesquisa quantitativa tem como objetivo analisar fatos a partir de quantidades através de ferramentas estatísticas. Já a qualitativa tem o objetivo de entender a explicação de algum evento, se há particularidades ou diferenças que não sejam quantificáveis ${ }^{(51)}$. 


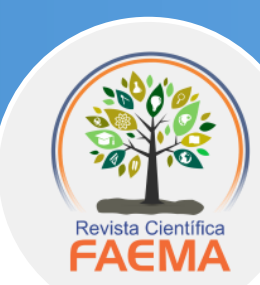

Já na pesquisa quanto à natureza, a presente pesquisa trata-se de uma pesquisa básica, pois tem como objetivo complementar outras pesquisas e contribuir de alguma forma com algumas particularidades sobre o tema. A pesquisa básica é teórica, feita por meio da pesquisa bibliográfica, tendo como foco o aprofundamento de determinado estudo que já possui algum conhecimento científico e tenha sido estudado por alguém (52). Além disso, também fornece informações novas e úteis para o progresso da ciência sem uma aplicação prática, abrangendo verdades e interesses geral da população ${ }^{(52)}$.

Em relação ao tipo de pesquisa quanto aos objetivos, o estudo classifica-se em descritiva, com a finalidade de descrever características de uma população, fenômeno, nela o assunto já é conhecido, então o intuito é conceder um novo entendimento a respeito da realidade existente ${ }^{(53)}$.

E por fim, quanto aos procedimentos técnicos, os meios utilizados para conceituar melhor o tema, e explaná-lo com mais facilidade, e assim alcançar os objetivos almejados, conceituar e descrever o tema com confiabilidade foi feito uma pesquisa bibliográfica e documental, em anos recentes, em sites como a Receita Federal, Governo Federal, artigos do google acadêmico e em sites de notícias.

A pesquisa bibliográfica permite um vasto meio para efetivar a pesquisa, pois é desenvolvida a partir de materiais já existente ${ }^{(54)}$. A pesquisa documental é realizada em "materiais que não receberam qualquer tratamento analítico, ou que ainda podem ser reelaborados de acordo com os objetivos da pesquisa” (54). Segundo Gil (54), ela é feita em documentos oficiais, jornalísticos, tabelas estatísticas, entre outros.

\section{Considerações Finais}

Ao longo dessa pesquisa foi visto que o IR é um tipo de tributo, sendo um dos impostos mais conhecido do Brasil, é declarado anualmente, e regulamentado pela lei vigente de cada ano, e diferente das taxas, ele é um imposto não vinculado, sendo de competência da União. 


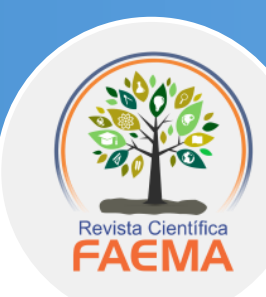

É necessário ter atenção ao preencher os dados no programa da declaração ofertado pela Receita Federal, pois se os dados apresentados não compactuarem com a realidade, pode acabar caindo na popular "malha fina".

Foi bastante perceptível os efeitos negativos causados pela desatualização da tabela do imposto de renda da pessoa física, afetando em grande parte a classe média, e aumentando assim o número de pessoas obrigadas a realizarem a declaração do IR. Percebe-se que desde o início a tabela já não vinha acompanhando a inflação de cada período, ocasionando a acumulação os resíduos, ou seja, a defasagem.

Além de tantas consequências mencionadas, a não atualização também faz com que a cada ano, a população obrigada a declarar o IR, pague mais impostos, pois a última atualização ocorreu em 2015, e mantendo-se tanto tempo congelada, acabou afetando diversos brasileiros, sendo que se caso acompanhasse a inflação, cerca de aproximadamente 10 milhões de pessoas estariam isentas, o que ocasionaria ao governo custos elevadíssimos.

O sistema tributário do Brasil é bastante injusto, e com a pandemia, a atualização da tabela acabou sendo adiada mais uma vez. Com real perdendo seu valor a cada ano, o Estado precisa tomar medidas cabíveis e urgentes, para isso será preciso fazer análises corretas para que com a atualização da tabela, ele não venha querer suprir essa perda que os cofres públicos sofrerão em outros impostos.

O Brasil possui imposto elevadíssimos, e mesmo pagando e declarando tudo corretamente os brasileiros são penalizados, seja na educação, saúde, segurança, porém mesmo com tantas falhas da distribuição do dinheiro arrecado, a população acaba não reivindicando seus direitos. Outro fato bastante interessante, é que mesmo sendo incluído na isenção por possuir doenças graves, o contribuinte deve provar isso com um laudo pericial. Apesar de ser injusto declarar um imposto de renda tão alto, a qual deveria estar isento, os brasileiros sentem impedidos de agir, pois apesar de terem mudado seus representantes, acaba ficando na mesma, e a atualização da tabela sempre é adiada, ficando sempre último lugar. 


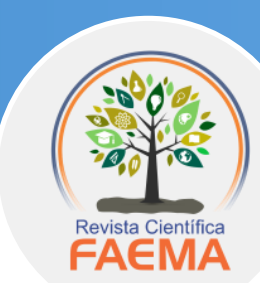

No Projeto de Lei que ainda está em discussão, será feito reajustes, e ficarão isentos aqueles que receberem até $\mathrm{R} \$ 2.500,00$ por mês, porém ainda está longe do valor que deveria ser, foi visto que para poder estar acompanhando a inflação, esse valor para isenção deveria ser de até $R \$ 4.057,23$, porém não é o que será. Apesar de tudo, a arrecadação de tributos beneficia muitos brasileiros, e nessa pandemia foi visto a importância do Sistema Único de Saúde- SUS, que mesmo tendo algumas falhas, salvou e acolheu muitas pessoas. Além do SUS, tem também o bolsa família, e o atual Auxílio Emergencial, mesmo parecendo pouco para alguns, para aqueles que recebem faz toda diferença.

A presente pesquisa agregou mais conhecimentos e curiosidades a respeito do imposto de renda, muitas pessoas apenas declaram por serem obrigadas, porém nunca pararam para estudar e examinar a tabela e toda a defasagem que está acumulada, e o quão alto paga em sua declaração do imposto de renda sem sua devida atualização. De maneira simples e compreensível foi apresentado o tema, e assim instigar as pessoas a buscarem seus direitos e também questionar os valores dos impostos que vêm sendo exigido pelo Estado e como é feito a destinação dos valores arrecadados.

\section{Referências}

1 Santana AS, Cruz WC, Silva A. Imposto de renda pessoa física: conceito e princípios. Revista eletrônica: Organizações e Sociedades. 2019;7(8):103-118. DOI: 10.29031/ros.v7i8.404.

2 Alvarenga D. Tabela do IR acumula defasagem de 113\%; saiba quanto seria o imposto com correção. São Paulo: G1 Economia; 2021 [citado em 15 abr. 2021]. Disponível em: https://g1.globo.com/economia/imposto-de-renda/2021/noticia/2021/02/19/tabela-do-iracumula-defasagem-de-113percent-saiba-quanto-seria-o-imposto-com-correcao.ghtml.

3 UOL. Com inflação e sem correção da tabela, brasileiro pagará mais IR em 2021. São Paulo: Economia UOL; 2021 [citado em 26 abr. 2021]. Disponível em:

https: //economia.uol.com.br/noticias/redacao/2021/01/12/receita-diz-que-tabela-doimposto-de-renda-tem-defasagem-de-113.htm.

4 Takar T. Bolsonaro não corrige tabela e obriga 10,5 milhões a pagar Imposto de Renda. São Paulo: Economia UOL; 2021 [citado em 29 abr. 2021]. Disponível em:

https: / /economia.uol.com.br/imposto-de-renda/noticias/redacao/2021/02/27/ir-2021-

defasagem-de-113-na-tabela-obriga-105-milhoes-a-pagarem-imposto.htm. 


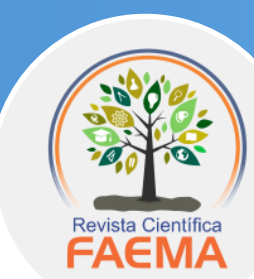

5 Ferreira R. 0 que é tributo?. Brasília: Jusbrasil; [s.d] [citado em 25 jun. 2021]. Disponível em: https://rfersantos.jusbrasil.com.br/artigos/224862277/o-que-e-tributo.

6 Hauer CC. Imposto de renda: a sua incidência (ou não) nas indenizações. Jornada LusoBrasileiras do CIDP (RJLB). 2020;6(1):193-232 [citado em 10 mar. 2021]. Disponível em: https://www.cidp.pt/revistas/rjlb/2020/1/2020_01_0193_0232.pdf.

7 Silva LFS. Breves Apontamos Históricos sobre Tributação no Mundo e no Brasil. São Paulo: Âmbito Jurídico; 2019 [citado em 20 abr. 2021]. Disponível em:

https: / /ambitojuridico.com.br/cadernos/direito-tributario/breves-apontamos-historicos-sobretributacao-no-mundo-e-no-brasil/.

8 Matos MLBS. A evolução histórica do Direito Tributário. [S.l]: Direito Net; 2007 [citado em 15 abr. 2021]. Disponível em: https://www.direitonet.com.br/artigos/exibir/3931/A-evolucaohistorica-do-Direito-Tributario.

9 Brasil. Ministério da Economia. Primórdios do Imposto de Renda no Mundo. Brasília: Receita Federal; 2015 [citado em 6 jun. 2021]. Disponível em:

https: / / receita.economia.gov.br/sobre/institucional/memoria/imposto-de-

renda/historia/primordios-do-imposto-de-renda-no-mundo\#wrapper.

10 Minardi J. Manual de direito tributário. 4 ed. Editora JusPODVM; 2017.

11 G1 Notícias. IR 2021: Receita recebeu 34,1 milhões de declarações, acima da expectativa. São Paulo: G1 Economia; 2021 [citado em 22 jun. 2021]. Disponível em: https://g1.globo.com/economia/imposto-de-renda/2021/noticia/2021/06/01/receita-recebeu341-milhoes-de-declaracoes-do-ir.ghtml.

12 Oliveira AS. Imposto de renda pessoa física [trabalho de conclusão de curso]. Fotaleza: Centro de Ensino Superior do Ceará; 2013 [citado em 6 jun. 2021]. Disponível em: https://www. faculdadescearenses.edu.br/biblioteca/TCC/CCO/IMPOSTO\%20DE\%20RENDA\%20P ESSOA\%20FISICA.pdf.

13 Sousa V. Quais são as punições para quem não declarar Imposto de Renda? [S.l]: Contábeis; 2020[citado em 20 mar. 2021]. Disponível em:

https: / /www.contabeis.com.br/noticias/46661/quais-sao-as-punicoes-para-quem-naodeclarar-imposto-de-renda/.

14 Brasil. Constituição da República Federativa do Brasil de 1988. Brasília: Presidência da República, 1988 [citado em 10 mar. 2021]. Disponível em:http://www.planalto.gov.br/ccivil_03/constituicao/constituicao.htm.

15 Dubard C. Imposto de renda: Como funciona a isenção do Imposto de Renda? São Paulo: Blog Magnetis; 2020 [citado em 25 mar. 2021]. Disponível em: https: / /blog.magnetis.com.br/isencao-do-imposto-de-renda/. 
16 Brasil. Ministério da Cidadania. Bolsa Família. Ministério da cidadania. - Brasília: MC; [s.d] [citado em 10 mar. 2021]. Disponível em: https://www.gov.br/cidadania/pt-br/acesso-ainformacao/carta-de-servicos/desenvolvimento-social/bolsa-familia-1.

17 Cavallini M. IR 2021: Como saber se sou isento?. São Paulo: G1 Economia; 2021 [citado em 22 jun. 2021]. Disponível em: https://g1.globo.com/economia/imposto-derenda/2021/noticia/2021/03/09/ir-2021-como-saber-se-sou-isento.ghtml.

18 Seu Dinheiro. Como declarar bitcoin e outras criptomoedas no imposto de renda. São Paulo: Seu Dinheiro; 2021 [citado em 25 maio 2021]. Disponível em: https: / / www.seudinheiro.com/2021/imposto-de-renda/como-declarar-bitcoin-no-imposto-derenda-2021/.

19 Brasil. Ministério da Economia. O que é Malha Fiscal?. Brasília: Receita Federal; [s.d] [citado em 25 mar. 2021]. Disponível em:

https://receita.economia.gov.br/orientacao/tributaria/declaracoes-e-demonstrativos/revisaode-declaracao-malha/o-que-e-a-malha-fiscal.

20 Hada D. Declaração retificadora: 0 que é e como fazer a retificação. São Paulo: Blog IR sem erro; 2020 [citado em 16 jun. 2021]. Disponível em:

https: //blog.irsemerro.com.br/declaracao-retificadora/.

21 Brasil. Ministério da Economia. Retificação da Declaração de Imposto de Renda. Brasília: Receita Federal; 2021 [citado em 16 jun. 2021]. Disponível em: https://www.gov.br/receitafederal/pt-br/assuntos/meu-imposto-derenda/preenchimento/retificacao. Acesso em: 16 jun. 2021. 22 Bueno S. Fiscal: Entenda o que é e como funciona o Fisco. Rio Grande do Sul: Blog Fazcomex; 2021 [citado em 6 jun. 2021]. Disponível em: https://www.fazcomex.com.br/blog/o-que-e-fisco/.

23 Nader D. Tabela Imposto de Renda 2021: entenda alíquotas e deduções previstas. São Paulo: Contábeis; 2021 [citado em 20 mar. 2021]. Disponível em:

https: / /www.contabeis.com.br/noticias/46166/tabela-imposto-de-renda-2021-entendaaliquotas-e-deducoes-previstas/.

24 Infomoney. Imposto de Renda 2021: como fazer a declaração. [S.l]: InfoMoney; 2021 [citado em 25 maio 2021]. Disponível em: https://www.infomoney.com.br/guias/imposto-de-renda/.

25 G1 Notícias. Imposto de Renda 2021: Como funciona a tabela do IR?. São Paulo: G1 Economia; 2021 [citado em 20 mar. 2021]. Disponível em: https://g1.globo.com/economia/imposto-de-renda/2021/noticia/2021/03/17/imposto-derenda-2021-como-funciona-a-tabela-do-ir.ghtml. 
26 Toro. Restituição de Imposto de Renda: o que é e como consultar. Belo Horizonte: Toro; 2019 [citado em 3 jun. 2021]. Disponível em:

https://artigos.toroinvestimentos.com.br/irpf/restituicao-imposto-de-renda-o-que-e-comoconsultar.

27 UOL. IR 2021: Já viu se a restituição caiu na conta? Receita paga hoje $1^{\circ}$ lote. São Paulo: Economia UOL; 2021 [3 jun. 2021]. Disponível em:

https://www.google.com/amp/s/economia.uol.com.br/imposto-de-

renda/noticias/redacao/2021/05/31/ir-2021-receita-paga-hoje-1-lote-de-restituicao.amp.htm.

28 Souza S. Imposto de Renda 2021 fica mais caro após ESTA atitude do governo. São Paulo: Terra; 2021 [citado em 12 maio 2021]. Disponível em:

https://fdr.com.br/2021/01/20/imposto-de-renda-2021-fica-mais-caro-apos-esta-atitude-dogoverno/.

29 Oliveira AC. Classificações de finalidade em pesquisa acadêmica. Paraná: Atena Editora; 2019 [citado em 6 jun. 2021]. Disponível em:

https: / /www.atenaeditora.com.br/blog/classificacoes-de-finalidade-em-pesquisa-academica/.

30 Kanitz MS, Soares FBC et al. Aumento dos custos tributários para as famílias brasileiras decorrente da não atualização monetária da tabela do Imposto de Renda Pessoa Física. In: Anais do XXV Congresso Brasileiro de Custos, 13 de novembro de 2018, Vitória, ES, Brasil. Vitória: ABC; 2018 [citado em 5 abr. 2021]. Disponível em:

https: //anaiscbc.emnuvens.com.br/anais/article/download/4429/4430. Acesso em: 05 abr. 2021.

31 Andrade E. O que é a defasagem da tabela do IR? Entenda como isso impacta no seu bolso. São Paulo: Terra; 2021 [citado em 12 maio 2021]. Disponível em:

https: / /fdr.com.br/2021/02/22/o-que-e-defasagem-da-tabela-do-ir-entenda-como-issoimpacta-no-seu-bolso/.

32 Ferrari H. Defasagem da tabela do Imposto de Renda chega a 113,09\%, diz Sindifisco. [S.l]: Poder 360; 2021[citado em 25 jun. 2021]. Disponível em:

https://www.poder360.com.br/economia/defasagem-da-tabela-do-imposto-de-renda-chega-a11309-diz-sindifisco/.

33 Banco Central do Brasil. O que é inflação?. Brasília: Banco Central do Brasil; [s.d] [citado em 6 jun. 2021]. Disponível em: https://www.bcb.gov.br/controleinflacao/oqueinflacao.

34 Redação RBA. Vem aí o Imposto de Renda 2021. Com a tabela defasada em mais de $100 \%$. São Paulo: Rede Brasil; 2021 [citado em 15 abr. 2021]. Disponível em: https: / /www.redebrasilatual.com.br/economia/2021/02/imposto-de-renda-tabela-defasada/. 
35 G1 Notícias. Sem correção desde 2015, tabela do IR faz brasileiro pagar mais a cada ano; veja impactos da defasagem. São Paulo: G1 Economia; 2020 [citado em 4 mar. 2021]. Disponível em: https://g1.globo.com/economia/imposto-de-

renda/2020/noticia/2020/03/13/sem-correcao-desde-2015-tabela-do-ir-faz-brasileiro-pagarmais-a-cada-ano-veja-impactos-da-defasagem.ghtml.

36 G1 Notícias. Tabela do IR está sem correção desde 2015; veja impactos da defasagem no imposto a pagar. São Paulo: G1 Economia; 2019 [citado em 4 mar. 2021]. Disponível em: https://g1.globo.com/economia/imposto-de-renda/2019/noticia/2019/03/08/tabela-do-iresta-sem-correcao-desde-2015-veja-impactos-da-defasagem-no-imposto-a-pagar.ghtml.

37 Vasconcelos E. Defasagem na tabela de IR: Tire todas as suas dúvidas sobre o assunto. São Paulo: Rede Jornal Contábil; 2021 [12 maio 2021]. Disponível em:

https://www.google.com/amp/s/www.jornalcontabil.com.br/defasagem-na-tabela-de-ir-tiretodas-as-suas-duvidas-sobre-o-assunto/\%3Famp.

38 Silveira D. Brasileiros gastam mais com jogos e apostas que com arroz, e mais com fumo que com legumes e verduras, aponta IBGE. São Paulo: G1 Economia; 2020 [12 maio 2021]. Disponível em: https://g1.globo.com/economia/noticia/2020/09/17/brasileiros-gastam-maiscom-jogos-e-apostas-que-com-arroz-e-mais-com-fumo-que-com-legumes-e-verduras-apontaibge.ghtml.

39 Instituto Brasileiro de Geografia e Estatística (IBGE). Agência de notícias IBGE. POF 20172018: famílias com até $\mathrm{R} \$ 1,9$ mil destinam $61,2 \%$ de seus gastos à alimentação e habitação. Rio de Janeiro: Agência IBGE Notícias; 2019 [citado em 16 maio 2021]. Disponível em: https: / /agenciadenoticias.ibge.gov.br/agencia-sala-de-imprensa/2013-agencia-denoticias/releases/25598-pof-2017-2018-familias-com-ate-r-1-9-mil-destinam-61-2-de-seusgastos-a-alimentacao-e-habitacao.

40 Santos SF. O enquadramento do contribunte nas tabelas do imposto de renda pessoa física (IRPF) [trabalho de conclusão de curso]. Rio de Janeiro: Universidade Federal Fluminense / Instituto de Ciências Humanas e Sociais Curso de Ciências Contábeis; 2017 [citado em 6 jun. 2021]. Disponível em: https: //app.uff.br/riuff/bitstream/1/7547/1/Sabrina\%20Freitas\%20dos\%20Santos.pdf.

41 Souza S. Imposto de Renda: Quais benefícios do governo devem estar na declaração?. São Paulo: Terra; 2021 [citado em 12 maio 2021]. Disponível em: https://www.google.com/amp/s/fdr.com.br/2021/04/22/imposto-de-renda-quais-beneficiosdo-governo-devem-estar-na-declaracao/amp/.

42 Santos A. Atualização tabela do IR: técnico aponta dificuldades para alterar faixa de isenção. São Paulo: Contábeis; 2021 [citado em 13 maio 2021]. Disponível em: https: / /www.contabeis.com.br/noticias/47005/atualizacao-tabela-do-ir-tecnico-apontadificuldades-para-alterar-faixa-de-isencao/. 
43 Máximo W. Defasagem na tabela do Imposto de Renda está próxima de 104\%. Brasília: Agência Brasil; 2020 [citado em 3 jun. 2021]. Disponível em: https: / /agenciabrasil.ebc.com.br/economia/noticia/2020-01/defasagem-na-tabela-doimposto-de-renda-esta-proxima-de-104.

44 Barbosa M, Hessel R. Correção da tabela de Imposto de Renda custará até R\$ 36 bilhões. São Paulo: Correio Braziliense; 2021 [citado em 6 jun. 2021]. Disponível em:

https://www.correiobraziliense.com.br/app/noticia/politica/2020/08/06/interna_politica,878 838/correcao-da-tabela-de-imposto-de-renda-custara-ate-r-36-bilhoes.shtml.

45 Caram B, Brant D. Guedes prepara mudança tímida na tabela do IR. Paraná portal. São Paulo: UOL; 2021 [citado em 6 jun. 2021]. Disponível em:

https://www.google.com/amp/s/paranaportal.uol.com.br/economia/guedes-preparamudanca-timida-na-tabela-do-ir/.

46 Agência Brasil. Primeiro caso de covid-19 no Brasil completa um ano: linha do tempo mostra enfretamento da pandemia no país. Brasília: Agência Brasil; 2021[citado em 13 maio 2021]. Disponível em: https://agenciabrasil.ebc.com.br/saude/noticia/2021-02/primeiro-caso-decovid-19-no-brasil-completa-um-ano.

47 Martello A, Mazui G. Gastos extraordinários do governo contra Covid caem de 524 bi em 2020 para 103 bi em 2021. São Paulo: G1 Economia; 2021 [citado em 1 jul. 2021. Disponível em:

https://www.google.com/amp/s/g1.globo.com/google/amp/economia/noticia/2021/04/23/ga stos-extraordinarios-do-governo-contra-covid-caem-de-r-524-bi-em-2020-para-r-103-bi-em2021.ghtml.

48 UOL. Economistas melhoram projeções para déficit primário e dívida bruta em 2021, aponta consultoria. São Paulo: Economia UOL; 2021 [citado em 9 nov. 2021]. Disponível em:

https: //economia.uol.com.br/noticias/reuters/2021/01/14/economistas-melhoram-projecoespara-deficit-primario-e-divida-bruta-em-2021-aponta-prisma.htm.

49 Agência Brasil. Receita Federal recebe 6,8\% a mais declarações do IR do que em 2021. São Paulo: R7- Economia; 2021 [citado em 9 jun. 2021]. Disponível em:

https://noticias.r7.com/economia/receita-federal-recebe-68-mais-declaracoes-do-ir-do-queem-2020-01062021.

50 Coutinho K. Metodologia de pesquisa TCC: saiba como definir.

São Paulo: Tua carreira; 2021 [citado em 31 jul. 2021]. Disponível em:

https://www.tuacarreira.com/metodologia-tcc/.

51 Coelho B. Tipos de pesquisa: abordagem, natureza, objetivos e procedimentos. São Paulo:

Blog da Mettzer; 2019 [citado em 21 maio 2021].

Disponível em: https://blog.mettzer.com/tipos-de-pesquisa/. 


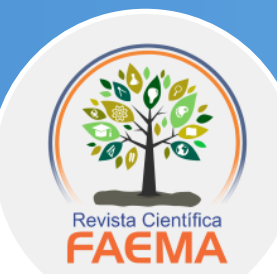

52 Prodanov CC, Freitas EC. Metodologia do trabalho científico: Métodos e Técnicas da Pesquisa e do Trabalho Acadêmico. 2 ed. Rio Grande do Sul: Universidade Feevale; 2013.

53 Duarte VMN. Pesquisas: exploratória, descritiva e explicativa. São Paulo: Monografias Brasil Escola; [s.d] [citado em 1 jun. 2021]. Disponível em:

https://monografias.brasilescola.uol.com.br/regras-abnt/pesquisas-exploratoria-descritivaexplicativa.htm.

54 Gil AC. Métodos e técnicas de pesquisa social. 6 ed. São Paulo: Atlas, 2008. 